\title{
Exploring the potential of using real-time traveler data in public transport disturbance management
}

\author{
Åse Jevinger ${ }^{1,2} \oplus$. Jan A. Persson ${ }^{1,2}$
}

Accepted: 24 July 2019 / Published online: 5 August 2019

(c) The Author(s) 2019

\begin{abstract}
New and emerging technologies, such as connected sensors, smartphones and smart cards, offer new possibilities to collect rich real-time information about travelers. Moreover, smartphones also enable travelers to actively share information, for instance, about their intended travel plans. This type of information can be used to improve public transport disturbance management. In this paper, the potential gain of collecting different types of information about travelers is explored to support action decisions made by public transport actors, during unplanned disturbances. Based on interviews and workshops, the paper provides a mapping between different information types and possible action decisions that can be supported. Furthermore, based on a literature review focused on current and potential technical solutions, a guidance to which solutions support which type of action decisions, is also provided. Amongst others, the results show that automated fare collection, which is one of the most commonly implemented systems providing real-time information about the traveler, can support a large number of action decisions relevant in unplanned disturbance scenarios. The technical solution providing the most extensive information, and thereby providing the best support for the action decisions, involves smartphone apps delivering user-generated information. The drawback with this solution is that it might violate privacy, and that it typically relies on the travelers providing relevant information voluntarily.
\end{abstract}

Keywords Public transport system · Disturbance management · Disruption management $\cdot$ Traveler information $\cdot$ Automated fare collection $\cdot$ Automatic passenger counting

Åse Jevinger

ase.jevinger@mau.se

1 Internet of Things and People Research Center, and Department of Computer Science and Media Technology, Malmö University, 20506 Malmö, Sweden

2 K2-The Swedish Knowledge Centre for Public Transport, Bruksgatan 8, 22236 Lund, Sweden 


\section{Introduction}

Information and communication technologies (ICTs) are predicted to change the use of transport systems in several ways (Cohen-Blankshtain and RotemMindali 2016). In particular, new and emerging technologies, such as the connected sensors, smartphones and smart cards, offer new possibilities to collect rich real-time information about travelers. Moreover, smartphones also enable travelers to actively share information, for instance, about their intended travel plans (Stelzer et al. 2016). Access to this type of information has the potential to improve the decisions and actions taken by public transport actors (Mayas et al. 2015). Particularly during unplanned disturbances, there is an increased need for more real-time information about travelers (Ibarra-Rojas et al. 2015). In recent years, unplanned disturbances caused by, for instance, train breakdowns, electrical failures, incidents and people running across train tracks have become a major concern for public transport operators. Parts of these problems derive from aging infrastructures, in combination with increasing demand and limited capacity. If the public transport actors are provided access to real-time information about the affected travelers, they may base their decisions during unplanned disturbances on the needs of the travelers as well as on the resources available. Thereby, a more efficient management of the public transport resources during disturbances, i.e. a more efficient disturbance management, might be established. For instance, information about where people are traveling, their special needs and their choice of transport route can be used to dynamically adjust the transport alternatives to the actual requirements, in situations with changed conditions due to disturbances. Possible adjustments might be, for instance, to hold a bus/train to avoid passengers missing a connection, to skip a stop if none of the passengers are planning to alight at that stop, or to order buses/taxis with sufficient capacity (Zeng et al. 2012; Ibarra-Rojas et al. 2015). Establishing an efficient disturbance management is important since, in the long run, this may lead to more people selecting public transport over private cars. Furthermore, in disaster situations (for instance during the earthquakes in Japan), there is a strong need to get a snapshot of the current travel streams, for security reasons rather than for quality of service reasons. In this paper, we make no difference between disturbance and disruption management, i.e. both relatively small perturbations that can be handled by updating the timetable and larger disturbances requiring more extensive measures, are addressed (Cacchiani et al. 2014).

Different technical solutions for collecting and providing information within public transport systems (PTS) have been investigated before, for instance, by Daduna and Voß as early as 1996 (Daduna and Voß 1996). Although many of the previous investigations focus on providing information about the PTS to the travelers, some has the opposite focus, i.e. providing information about the travelers to the PTS. Literature shows that information about travelers can be collected for different purposes and by different means of technologies. For instance, some studies have investigated how data retrieved from smart card systems designed for automated fare collection, can be utilized (in addition to fare collection) for 
traffic line planning, terminus planning, studying the transport network usage etc. (van Oort et al. 2015; Arnone et al. 2016; Fujiyama and Cao 2016). Furthermore, different types of sensors can also be used to collect information about travelers. For instance, smartphone sensors can be used to capture and reconstruct the travelers' journey and modes of transport (Stenneth et al. 2011; Kostakos et al. 2013). This information can then be used to understand passenger behaviors. Mobile phone positioning, which represents a relatively reliable, inexpensive but imprecise technology, can also be seen as a viable approach for collecting similar information (Lee et al. 2016). Naturally, the passengers themselves may also actively share their data, for instance by checking in on a specific travel route via a smartphone, or by means of social media or crowdsourcing platforms (Lau and Ismail 2015). This type of information sharing often provides the public transport companies with insight into problems or other passengers with real-time traffic information (Crawford 2013).

Thus, the idea of collecting data from travelers is not new. However, most of the current approaches collect data for post-travel analysis purposes. In particular, the data collected is commonly not used as input to real-time disturbance management (Stelzer et al. 2014). Research within disturbance management has so far mainly focused on the issues of timetable readjustment, and rolling stock or crew rescheduling, including decision support methods from the operator perspective (e.g. Kiefer et al. 2016; Nikolić et al. 2015; Shakibayifar et al. 2018; Törnquist 2006). Some of these studies focus mainly on disturbance management from the aspects of the operations managers (Ghaemi et al. 2017) whereas others also take the quality of service perceived by the passengers into account (Corman et al. 2017). However, real-time data about travelers, such as traveler flow data, is normally not used in these rescheduling decision-making processes (Josyula and Törnquist Krasemann 2017). Instead, disturbance management has been forced to rely on non-real time traveler information collected via traditional travel surveys. Some of these surveys focus on traveler flows and few on typical traveler behaviors during unplanned disturbances (Currie and Muir 2017). Models for how traveler behaviors and flows are affected by information sharing during public transport disturbances (including social media), can also be used (Hua and Ong 2018). To the best of our knowledge, there are no previous studies addressing the potential gain of collecting real-time information about travelers, from the aspects of improving disturbance management during unplanned disturbances. We have also failed to find previous studies about which type of information is relevant and how it can be collected.

Jevinger and Persson $(2016,2019)$ identified a set of information-related problems during unplanned public transport disturbances, based on interviews with a number of transport actors affected by such disturbances. Information-related problems were also gathered from workshops with these and other similar actors. The results from this work showed that real-time information about the travelers, in particular from and to where people are traveling and when, can be used to solve several of the problems that arise during disturbances. As a consequence of these results, and as an attempt to decrease the research gap identified above, this study contributes with knowledge (a high level assessment) of the potential gain of collecting different types of information about travelers to support action decisions 
taken by public transport actors during unplanned disturbances. The study also provides information of how this information can be collected. Given that there are a number of different types of information about travelers and a number of different action decisions that can be made based on these, we set out to provide a mapping between different information types and possible action decisions that can be supported. Further, by also looking at current and potential technical solutions (e.g. different check-in systems ${ }^{1}$ ), and their included information types, we provide guidance to which solutions support which type of action decisions. This information can be used by public transport actors to better understand how they might utilize the information collected in existing ICT systems to improve disturbance management, and the consequences/potentials with different types of new ICT systems. Thus, the paper is only focused on information to the transport actor, not information to the traveler. Furthermore, we restrict the study to information on short- to mid- distance travelers, e.g. commuters, since disturbances in long-distance journeys versus disturbances in short- to mid-distance journeys commonly require different types of actions.

In PTS, there are often repeating patterns that can be used to create rather good estimates of where passengers are and their intended exit points. In this study, we focus on information solutions and types that can both improve the quality of predictions based on historical data, and replace estimates based on historical data. Our hypothesis is that the usefulness of historical data to predict the current state quickly deteriorates in situations of disturbance, since these situations change normal behaviors and conditions. For instance, people may change their plans and take own actions (when possible), meaning that they may not stand still waiting for the next train or replacement traffic. In particular, the timing and the exact content of the information given to travelers may affect their decisions. Thus, what happens in the system during unplanned disturbances, is typically not well known today.

The remainder of the paper is structured as follows. Section 2 describes the methodology applied. Section 3 presents the results and analysis, and is divided into three main parts. In the first part a set of problems and potentials, that can be related to a lack of real-time information about the traveler in unplanned disturbance management, is identified based on information gathered from interviews and workshops. These problems and potentials enabled us to distinguish a number of possible action decisions that can be made by transport actors during unplanned disturbances, as well as the corresponding real-time information about travelers required. We also provide a mapping of the information about travelers to the possible action decisions. In the second part of Sect. 3, a set of technical solutions for collecting the information about travelers, required by the action decisions, is identified based on a literature review. We also provide a mapping of the information about travelers to the possible technical solutions. The last part of Sect. 3 presents a concluding analysis and discussion. In particular, it explains how the previous two mappings can be

\footnotetext{
1 By check-in systems we mean systems with information about travelers' current status (e.g. location and special needs) and/or future travel plans that may be relevant for disturbance management.
} 
used to assess which technical solutions can support which action decisions. Finally, Sect. 4 summarizes the conclusions and outlines the future work.

\section{Methodology}

This study has been conducted as follows:

1. From the set of problems identified in semi-structured expert interviews and workshops (Jevinger and Persson 2016, 2019), all problems that can be related to a lack of real-time information about the traveler in unplanned disturbance management were extracted. The aim of this research step was to investigate which of the current problems that exist today might be mitigated or solved by access to information about the traveler. The workshop focused on collaboration during public transport disturbances in Sweden, and had 60 participants, ranging from train drivers and administrators to CEOs (Jevinger and Persson 2016, 2019). The results from the workshop discussions were written down by the participants themselves. The interviews focused on public transport within the Scania County in Sweden and involved the following actors: the Swedish Transport Administration, Skånetrafiken (administration responsible for public transport in the Scania County), a train operator (responsible for regional rail services in the Scania County), a bus operator (responsible for city bus traffic in several cities within the Scania County), and a taxi company (operating in the Scania County) (Jevinger and Persson 2016, 2019). The interviews were conducted by two researchers who documented the results. This documentation was then verified by the interviewed actors.

2. At a workshop organized by Samtrafiken ${ }^{2}$ in spring 2017, we collected information about the transport actors' views on the potentials with information about travelers. The aim of this research step was to investigate what could be improved in disturbance management, by access to real-time information about the traveler during unplanned disturbances. The workshop questions focused on what type of information about travelers would be beneficial to have, and what action decisions that information would enable (see Appendix 1). Before the workshop, these questions were revised by the organizer of the workshop, who had knowledge about the workshop participants and by an external researcher with extensive experience in research methodologies including workshops. The workshop had about 40 participants with the same work composition as in the workshop performed by Jevinger and Persson $(2016,2019)$. The participants were divided into seven focus groups, with one discussion leader each. All groups discussed the same questions. The discussion leaders registered the results from the group discussions in a software application (under supervision of the other group participants). After

\footnotetext{
2 Samtrafiken is a service development company owned by nearly 40 different traffic actors, each with equal percentage of ownership (http://www.samtrafiken.se). Samtrafiken acts as an independent party where common challenges are discussed and met with collaborative solutions.
} 
the workshop, all results were collected from the application and all unique inputs were identified.

3. By performing a thematic content analysis of the extracted problems and the results from the above workshop focusing on the potentials, we were able to:

a. identify possible action decisions that can be made by transport actors during unplanned disturbances, and which can be supported by real-time information about travelers,

b. identify the corresponding information types about travelers that are required by/support the action decisions (based on analysis of the identified action decisions), and

c. map the information about travelers to the possible action decisions.

4. In order to investigate possible technical solutions for collecting the identified information types in real time, we conducted a literature review on both implemented and suggested solutions. Based on this, we were able to:

a. identify possible technical solutions for collecting this information about travelers, and

b. assess the extent to which these solutions provide support for collecting the different identified information types, i.e. map the information about travelers to the technical solutions.

5. The mapping of possible action decisions and possible technical solutions to the different information types could then be used to assess which technical solutions can support which action decisions.

Thus, the results from this study consist of an identification of the action decisions relevant for disturbance management that can be supported by real-time information about travelers (3a), identification of the corresponding relevant information types about travelers (3b), and identification of possible technical solutions for collecting this information (4a). Additionally, mappings between the action decisions and information types (3c), and between the technical solutions and the information types (4b), as well as an assessment which technical solutions can support which action decisions, are included (5).

Since the interviews and workshops conducted in the previous study, as well as the workshop conducted within this study, were restricted to Swedish actors only, the corresponding results are based on a Swedish perspective. The literature review, though, had an international perspective. Consequently, the identified connection between types of decision actions and supporting technical solutions via information types should be relevant also for a non-Swedish setting.

The literature review was conducted according to the guidelines provided by Webster and Watson (2002). However, instead of searching through leading journals and conference proceedings, the starting set of papers was generated through database searches. These database searches included EBSCO Host Academic Search Elite, Scopus, Web of Science and Google Scholar, and the search string public transport, in combination with check-in, sensor, Bluetooth, 
RFID, Automated Fare Collection, Automatic Passenger Counting and Advanced Traveler Information Systems. We also included searches using public transport in combination with disturbance or disruption; however, due to a huge amount of irrelevant hits, we added traveler, real-time and information to these searches. The database searches resulted in a starting set of 12 papers. Based on these, backward and forward snowballing was then applied. All research articles included were either peer-reviewed journal articles or conference articles. In order to focus the literature review on the most recent technical achievements, only research articles published in 2010 or after were considered. Furthermore, only solutions for collecting information about travelers in real time were considered, i.e. collecting information by means of, for instance, interviews or questionnaires, was not included in the literature review. In addition to identifying technical solutions presented by the research community, the selected papers also identified solutions currently in operation. Based on these, we extended the search to also include Google, in order to gather more information about these solutions. The final set of references selected for the literature review consisted of 29 research papers and 5 other references.

\section{Results and analysis}

\subsection{Problems and potentials}

In disturbance management, more or less real-time action decisions are needed. For instance, decisions of ordering replacement traffic need to be taken as quickly as possible. If the situation can be characterized as reoccurring, these decisions can be based on plans or rules of thumb, developed beforehand. However, even if the situation is reoccurring, the actual number of travelers and their end destination may vary. This is particularly the case during disturbances that are consequences of other disturbances. In these situations, some travelers may have replanned their journeys and/or simply missed connections which they normally take when commuting.

The problems related to a lack of real-time information about the traveler in unplanned disturbance management, expressed during interviews and workshops, are listed in Table 3, Appendix 2 (derived from Jevinger and Persson 2016, 2019). The potentials (potential benefits) with having information about travelers in unplanned disturbance management, expressed during a workshop, are listed in Tables 4 and 5, Appendix 2.

As mentioned above, the problems and potentials have been identified based on a Swedish perspective. In Sweden, more than $90 \%$ of the total public transport supply is tendered out through competitive contract-awarding procurement methods (Vigren 2017). This means that open competition traffic operates alongside subsidized traffic. The state's infrastructure is still maintained by a national authority. As a consequence of the deregulation, the number of actors has increased, and thereby also the number of decision levels and IT-systems, which has made the cooperation and coordination more challenging than before. Other countries, for instance in 
central and Western Europe, such as Britain, Norway and Germany have also deregulated the public transport market (van de Velde 2014).

The transport actors involved in identifying the problems and potentials are the Swedish transport administration, a train operator, a bus operator, a taxi operator, and the regional public transport administration responsible for public transport in Southern Sweden. The Swedish transport administration is, amongst others, responsible for the long-term infrastructure planning, construction, operation and maintenance of state roads and railways. The regional public transport administration has the overall responsibility for bus and rail traffic, as well as transportation services for people with special needs. To fulfil these responsibilities, the regional public transport administration acts as the ordering party towards the train and bus operators, in Southern Sweden.

Based on the problems and potential descriptions in Tables 3, 4 and 5, Appendix 2, a number of action decisions that can be made by transport actors to improve the management of unplanned disturbances, can be distinguished. These action decisions are listed in the first column of Table 1, with references to the corresponding problems and potentials. It is worth noting that regular traffic replanning/capacity reallocation is one of the action decisions, since regular bus lines are seen by the actors as unexploited resources for disturbance management that could, for instance, be instructed to wait for train passengers or be strengthened with extra capacity. Furthermore, information about the travelers' special needs is regarded as an enabler for creating and informing about personalized alternative routes.

Each of the identified action decisions requires, or is supported by, different types of information about travelers. These information types are listed in the first row in Table 1. Some of the information types in Table 1 reflect the planned journey. Due to disturbances, this plan, and thereby also the corresponding information types, might change. Depending on the technical solution selected for collecting this information, the actors may or may not have knowledge of these changes (see Sect. 3.2). The remaining part of Table 1 shows the assessed mapping between the identified action decisions and the different information types. The letters stand for:

- A: Level of anonymity

- i: Entirely anonymous

- ii: Anonymous but individual activities can be traced via some identification key

- iii: Real identity known or person can be reached via some identification key

- B: Ratio of travelers for which the information has to be known

- i: Partial

- ii: Full

$\mathrm{Bi}$ indicates that information from only a part of the travelers is sufficient to enable the corresponding action decision whereas Bii indicates that information from all travelers is required. Please note that none of the action decisions in Table 1 


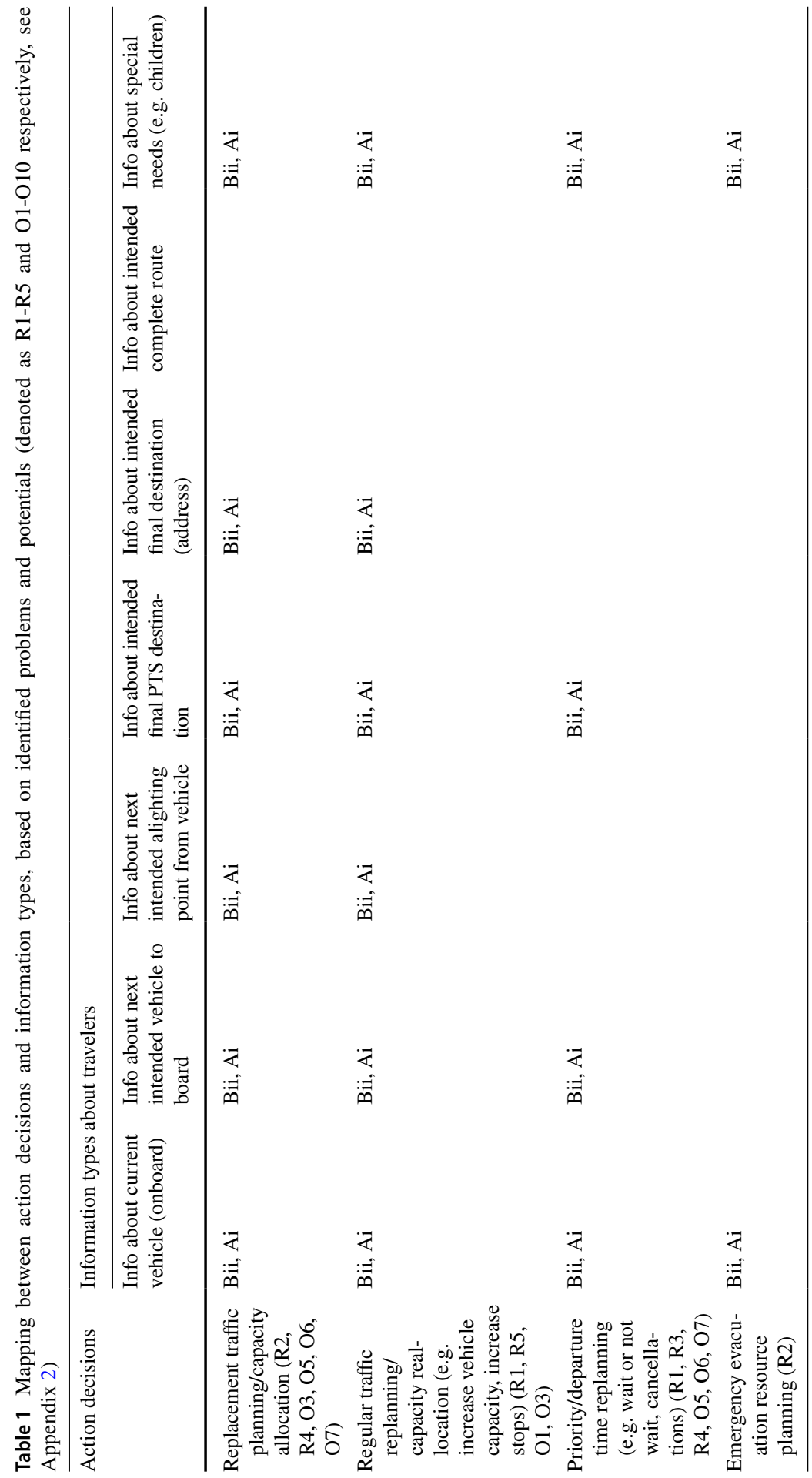




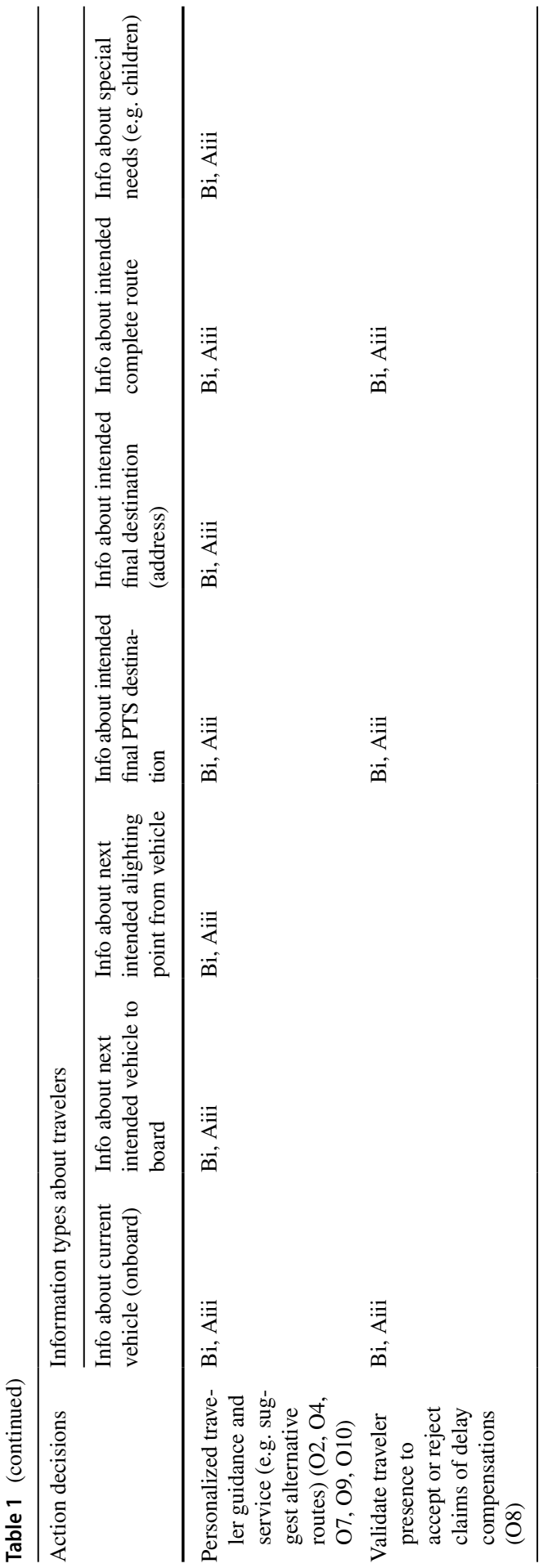


require information of anonymity level Aii. The reason for still including this level in the list above is that it is relevant for Table 2.

In order to obtain a correct replacement traffic planning/capacity allocation, traveler information about current vehicle, and information about next intended vehicle to board are most valuable (see Table 1). The former information type is required to account for travelers that are currently onboard a vehicle, which will stop at some place from where replacement traffic is needed. The latter information type is required to account for travelers who are currently waiting at, or on their way to, some place from where replacement traffic is needed. If information about the next intended alighting point from vehicle, information about intended final PTS destination or information about intended final destination is available as well, the route of the replacement vehicles could also be efficiently planned. For instance, the latter information could be used for adding more stops to the route, allowing for a more efficient journey for the traveler. Furthermore, information about special needs allows for providing personnel and vehicles adapted to these needs.

The information types valuable for replacement traffic planning/capacity allocation are also valuable for regular traffic replanning/capacity reallocation, for identical reasons. For priority/departure time replanning, traveler information about current vehicle, and information about next intended vehicle to board are highly important, since this information reveals how many travelers are affected by a delayed vehicle, and how many are expected to change vehicles. Thereby, the importance of holding a vehicle or prioritizing one vehicle over another, can be evaluated. Also information about intended final PTS destination can be used to predict expected transits. For instance, a traveler riding with a train from A to B, but having $\mathrm{C}$ as the final PTS destination, will probably catch a train (or some other transport means) from $\mathrm{B}$ to $\mathrm{C}$ as well. Information about special needs allows for better decision support. For instance, information that there is a school class onboard a train, heading for the airport, could be useful when deciding train priorities during a disturbance.

For emergency evacuation resource planning, traveler information about current vehicle, i.e. how many travelers are onboard, is important since this determines the amount of staff required for the evacuation. Information about special needs is also valuable since this information allows the operator to adjust the evacuation to special needs. For instance, there might be travelers in wheelchairs.

For personalized traveler guidance and service, all information types are useful for providing as good personalized service as possible. Traveler information about current vehicle, information about next intended vehicle to board, information about intended final destination, and information about special needs are the most important since these information types allow for providing personalized travel plan alternatives. The other information types can be used to enhance the service, for instance, by notifying the traveler when it is time to get off.

In order to validate traveler presence to accept or reject claims of delay compensations, traveler information about current vehicle and information about intended final PTS destination are important (given that the claims concern the entire journey till the final PTS destination). With these information types, the presence on a 
vehicle and the intended final PTS destination can be validated. If information about intended complete route is also available, the claims can be made more differentiated. For instance, a traveler might prefer a certain route over the fastest one, for personal reasons.

\subsection{Literature review: solutions}

This section provides the results from the literature review. The research studies included in the review propose different application areas for their solutions and information collected about travelers. These application areas can be categorized as follows:

- Create a better understanding of the PTS, e.g. concerning PTS timeliness and vehicle-kilometers (Uniman et al. 2010; Pelletier et al. 2011; Wang et al. 2011; Barabino et al. 2014).

- Create a better understanding of travelers' PTS usage behavior (both individual behaviors and aggregated travel patterns), e.g. for transport network planning, terminus planning, urban planning, modeling, marketing or research purposes (Oberli et al. 2010; Lathia and Capra 2011; Pelletier et al. 2011; Stenneth et al. 2011; Wang et al. 2011; Munizaga and Palma 2012; Kostakos et al. 2013; Ma et al. 2013; Barabino et al. 2014; Nitsche et al. 2014; Arnone et al. 2016; Fujiyama and Cao 2016; Stelzer et al. 2016; Zhong et al. 2016).

- Improve short-term forecasting, e.g. crowdedness, travel times (Lathia et al. 2010; Ceapa et al. 2012; Handte et al. 2014).

- Perform "what if" and consequence analyses, e.g. cost analysis of a broken connection (Lathia and Capra 2011; McMullan and Majumdar 2012; Barabino et al. 2014; van Oort et al. 2015; Stelzer et al. 2016).

- Provide personalized travel information and itineraries, including reroute information in case of disturbances (Pelletier et al. 2011; Stelzer et al. 2016).

- Charge travelers for their journeys (Zeller 2013; Narzt et al. 2015; Zöscher et al. 2015).

Depending on the goal of a research study, different types of information are collected. All of the information types identified in Sect. 3.1 are covered by the studies included in the literature review, though. The many application areas described above show that different types of benefits could be obtained by collecting information about travelers. However, only one of the studies specifically identifies improved disturbance management as a reason for collecting information about travelers (Stelzer et al. 2016), and most of the studies do not use the information in real-time, but rather use it for long-term decisions and analysis. However, many of the studies identify application areas that are clearly related to disturbance management; in particular, those connected to short-term forecasting improvement as well as "what if" and consequence analyses. 
Next, a summary of different technical solutions that could be used for collecting the different information types, identified by the literature review, to improve disturbance management, is provided.

\subsubsection{Review summary}

Many PTS actors today apply smart card Automated Fare Collection (AFC) systems for ticket charging and validation. In these systems, the traveler either carries a contactless smart card, which communicates wirelessly with a local reader, or has a contact smart card, which the traveler places in direct contact with or close (within a few centimeters) to the reader (Pelletier et al. 2011). RFID and NFC communication technologies are often applied for these types of smart cards (e.g. Oyster card in London and Access card in Stockholm). The smart card detection may occur at PTS entrance and exit (Lathia and Capra 2011; Zhao et al. 2017; van der Hurk et al. 2014), at vehicle entrance or on platform, waiting to board a certain vehicle (Wang et al. 2011; Munizaga and Palma 2012; Ma et al. 2013; Arnone et al. 2016), at vehicle entrance and exit (Ma et al. 2013; van Oort et al. 2015; Arnone et al. 2016), or when onboard via a contactless smart card (Zeller 2013) (cf. Table 2). Detection may also occur only when entering a PTS. However, in order to estimate the number of passengers in a vehicle, which represents the lowest level of information in Table 1 that may trigger different action decisions by the PTS actors in disturbance situations, more information than just the boarding point of an entire PTS is usually needed. Therefore, we here, and for the remainder of this paper, only consider systems that provide more information than just the PTS entrance.

The data collected by smart card AFC systems may be very useful for PTS actors, both in their daily operational work and in their more long-term tactical and strategical planning processes (Pelletier et al. 2011). Normally, the date, time and card numbers are available and recorded (Pelletier et al. 2011). In some cases, the boarding location is also accessible, either in the form of precise information, such as geographical position or station ID (Lathia and Capra 2011; Wang et al. 2011; Munizaga and Palma 2012; Ma et al. 2013; van Oort et al. 2015; Arnone et al. 2016), or in the form of estimated information, such as line number or vehicle ID in combination with time (Ma et al. 2013). For both the estimated and precise boarding location information, some data processing and data connection activities might be needed before the traveler location data can be identified. For instance, a mapping between automated vehicle location (AVL) data and recorded check-in data might be needed to generate the precise boarding location. In this paper, we are only interested in systems that include boarding location in some form, since this information is needed to estimate the number of passengers in a vehicle, which represents the lowest level of information in Table 1. Based on the boarding location, the entire route can be predicted using one of the trip-chaining methods available in literature (Zhao et al. 2007; Munizaga and Palma 2012; Arnone et al. 2016). In general, these methods are designed for contact smart card systems that only require the traveler to check in but not out of a journey. They often base their predictions on current and historical boarding data, PTS time tables and a set of assumptions. The accuracy 
of the results thereby varies. In order to improve the alighting data from such systems, Zöscher et al. (2015) suggest complementing the active check in with a passive check out (meaning that no active action is required by the traveler). They argue that an active check out might be experienced as inconvenient and counter- intuitive, and that a passive check out would yield the same type of data as an active check out. In the solution proposed by Zöscher et al. (2015), travelers check in actively via HF RFID, and check out passively via UHF RFID, using HF/UHF dual-band RFID smart cards.

In recent years, new technologies for AFC have appeared on the market. For instance, Deutsche Bahn's Touch\&Travel system allows travelers to pay for a journey by checking in and out via an app in their smartphones (McLean 2011). The location of the traveler is identified in one of several ways: the smartphone's GPS may provide the location, the traveler may use the smartphone to read a local QR barcode identifying the station, the traveler may use the smartphone to read a local NFC tag identifying the station, or the traveler may type in the station identification number manually. Finžgar and Trebar (2011) have developed a prototype with similar functionality, where travelers pay for their journeys by using smartphones to read station barcodes or NFC tags, at the beginning and end of the journeys. In Singapore, they have also applied an NFC-based system, in which the travelers check in and out by tapping their smartphones on fare gantries or readers on buses (Ezlink 2017). As an alternative to reading a local QR code using a smartphone, the regional public transport administration in southern Sweden has launched a system that validates traveler tickets by letting local bus readers read QR codes displayed in the traveler's smartphone app (Skånetrafiken 2017). In all these systems, the ticket detection occurs at PTS entrance and exit (e.g. Ez-link (2017)), at vehicle entrance or on platform (e.g. Skånetrafiken 2017), or both at vehicle entrance and exit (e.g. McLean (2011), Finžgar and Trebar (2011)) (cf. Table 2). The ticket detection requires an active action by the traveler. However, AFC solutions that do not require active actions from the travelers, i.e. where the travelers unconsciously obtain their tickets while traveling, also exist. Narzt et al. (2015) propose a system, in which the traveler carries a bluetooth low energy (BLE) beacon or a BLE-enabled smartphone. The BLE-device broadcasts a unique ID, which is received by an On-Board System (OBS). Thereby, all onboard travelers can automatically be detected and charged for their journeys. Trapeze Group Europe, together with Albis Technologies, has developed a similar solution based on active RFID (Zeller 2013). The traveler carries an active RFID card (ComfoAccess ${ }^{\circledR}$ card), which is detected by an OBS and used to determine whether the passenger is currently inside or outside a vehicle. Both these solutions provide traveler detection when onboard (cf. Table 2).

One problem common for all AFC systems is that they might not provide complete data due to fare evasion behaviors. Studies on fare evaders show that some demographic characteristics, such as sex, age, education, employment and origin correlate with unethical behavior in terms of fare evasion (Bucciol et al. 2013; Barabino et al. 2015). Furthermore, Delbosc and Currie (2016) demonstrate that the typical fare evader often shows distinct personality and behavioral characteristics. The extent of this problem varies from region to region and the practical possibilities for fare evasion also vary (depending on ticket control/charging procedures). Barabino 
et al. (2015) also show that more short-term circumstances may affect fare evasion, such as access to alternative transport modes, trip length, satisfaction with provided service, inspection levels and knowledge of fines.

Another application field for travel data collection includes surveys of travel habits and utilization of the public transport network. Today, travel surveys are commonly conducted with costly and time-intensive questionnaires or interviews (telephone or personal interviews, mailed questionnaires, web-based questionnaires, etc.). However, new approaches are evolving that take advantage of emerging technologies to deliver more efficient travel survey data. Some of these approaches provide detection when onboard (cf. Table 2). For instance, Kostakos et al. (2013) have developed a system that continuously scans the inside of a bus for Bluetooth devices. The information about the number of Bluetooth devices, together with positioning data from the onboard GPS, is used to reconstruct the travelers' origin and destination, as well as the traveling route. However, only $12.8 \%$ of the travelers were shown to carry Bluetooth-enabled devices. In a similar study, conducted by Handte et al. (2014), the presence and absence of WLAN-enabled mobile devices inside a vehicle are determined by continuous scans for probe requests, which are periodically transmitted by the phones. Hereby, the number of onboard travelers can be estimated.

Other survey approaches provide continuous detection (cf. Table 2), meaning that the traveler is continuously monitored, even when being outside the PTS. For instance, Lau et al. (2011) have developed a system that, amongst others, continuously collects GPS data with timestamp traces from the travelers' smartphones. Different types of incentives are created to make the travelers join this data collection scheme. The collected (anonymized) data can then be accessed by third-party developers via a web-based Application Programming Interface (API). Continuous traveler detection can also provide data for determining the current mode of transport. For instance, Nitsche et al. (2014) have presented an approach for collecting data from the smartphone accelerometer and GPS receiver, as well as positioning data from the cellular network. Based on this information, individual trips of the person carrying the smartphone can automatically be reconstructed and trip legs can be classified into one of eight different modes of transport (walk, bicycle, motorcycle, car, bus, electric tramway, metro and train) (Nitsche et al. 2014). Stenneth et al. (2011) similarly use information from the travelers' smartphone GPS receivers, in combination with real-time data on bus locations, rail line route data and bus stop location data, to detect transport mode (walk, bicycle, car, bus, aboveground train and stationary).

Some systems collecting traveler information focus on Automatic Passenger Counting (APC). APC technology is designed to measure the number of on-board passengers, for instance by means of infrared sensors or video image (Barabino et al. 2014). The travelers are often detected at vehicle entrance and exit, for instance by sensors installed over the vehicle doors (Oberli et al. 2010; Barabino et al. 2014); however, detection when onboard also exists (Kotz et al. 2015) (cf. Table 2). Oberli et al. (2010) propose a solution based on RFID tags embedded in plastic cards, which are detected by readers mounted in the door openings. They suggest implementing the RFID tag onto a smart card ticket. Thereby, the ID of each traveler passing, for instance, a bus door, can be detected. Kotz et al. (2015) apply a different 
approach to APC. They have conducted experiments on a system that measures the pressure inside the vehicle air bag suspension system, which directly correlates to vehicle mass. Based on the vehicle mass variations, discrete boarding and alighting events can be detected.

Additional initiatives providing real-time information about the traveler include user-generated information from smartphone apps (cf. Table 2). Stelzer et al. (2016) propose an approach for bidirectional information and communication between the traveler and transportation company. In this approach, an app installed in the travelers' smartphone is used to transmit information from the traveler to the transport actor. Amongst others, information related to the planned trip, including destination, route (including stopovers and interchanges) and time, is transmitted from the app.

As described above, the regional public transport administration in southern Sweden has launched an app, in which the QR-code described above is shown (Skånetrafiken 2017). In addition to one-way tickets, this app enables zone-based tickets with detection at vehicle/PTS entrance, i.e. zone to zone tickets (cf. Table 2). The travelers can buy a ticket for a small, medium or large zone, and this information might be used to get a picture of possible destinations.

Finally, most PTS operators also offer traditional tickets specifying complete journeys, including time and route, which provide a type of real-time information about travelers (cf. Table 2) (Deutsche Bahn 2017). These types of tickets may be used by all or only a part of the travelers (e.g. elderly). However, since tickets that have been bought might not actually be used, the information provided may be incomplete. This problem might be solved with mandatory ticket detection, for instance onboard.

\subsubsection{Mapping of technical solutions to information types}

The technical solutions described above can be categorized as shown by the first column of Table 2. The references to the corresponding research studies/implemented systems are also included. Table 2 also shows the mapping between the identified solutions and the different information types that each of the solutions can provide. Since there are individual differences between the implementations of the technical solutions included in the literature review, they often enable different precision of the provided information. Therefore, we have chosen to only illustrate the highest achievable information precision that can be collected with the different solutions, in Table 2. The letters in Table 2 stand for:

- A: Level of anonymity

- i: Entirely anonymous

- ii: Anonymous but individual activities can be traced via some identification key

- iii: Real identity known or person can be reached via some identification key

- B: Ratio of travelers for which the information can be known

- i: Partial

- ii: Full 


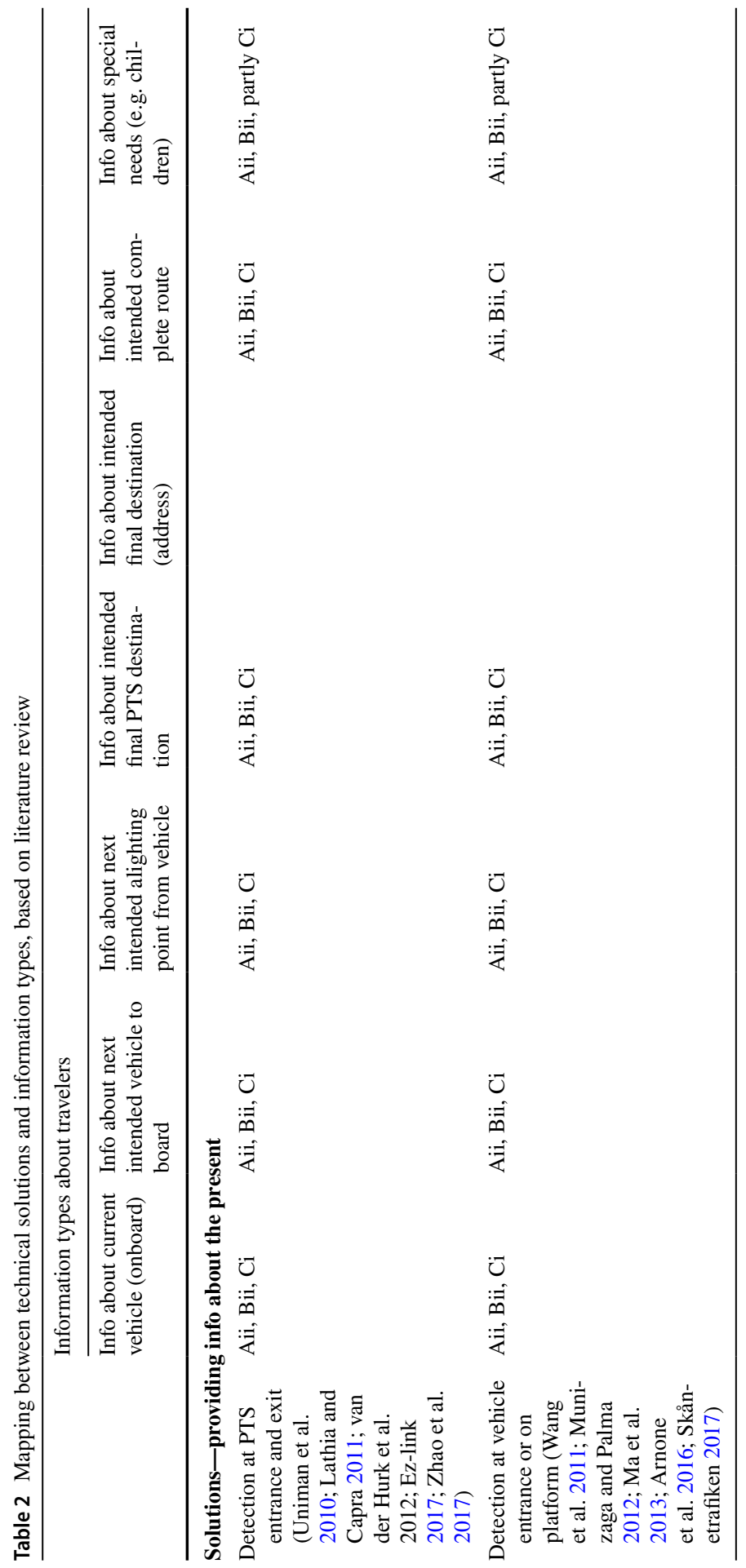




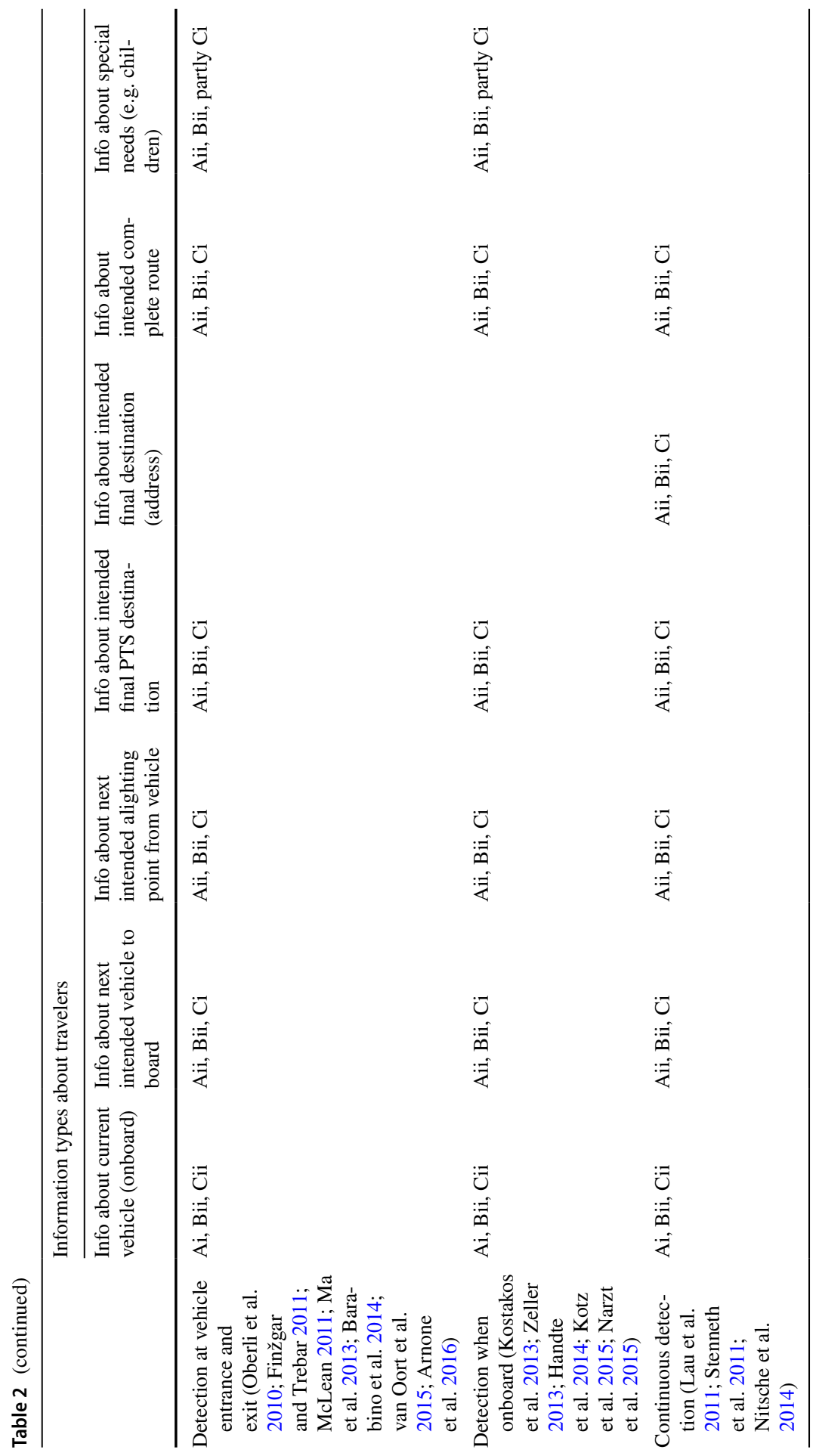




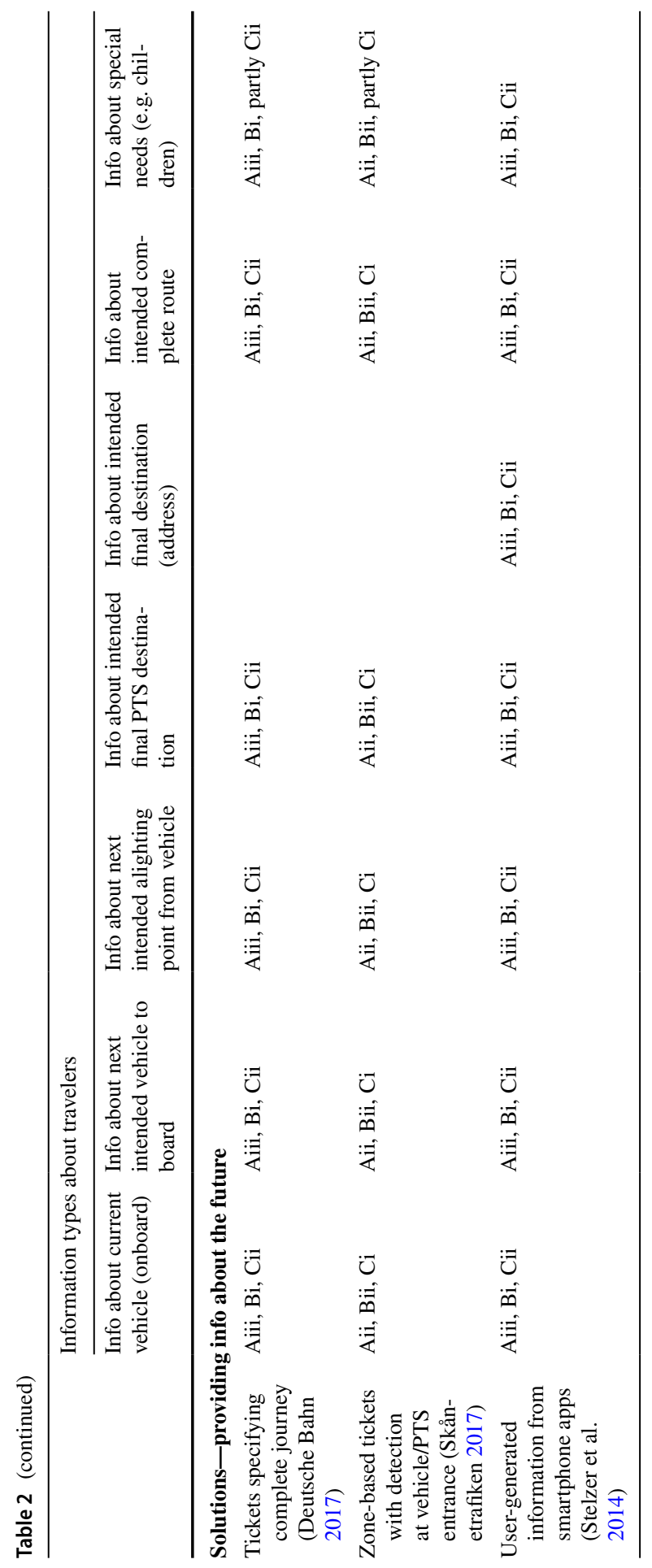


- C: Precision of the provided information

- i: Must be estimated

- ii: Has the potential to provide exact information (depending on implementation)

As described in Sect. 2, all technical solutions identified are able to provide realtime information about travelers. This means that exact information can be obtained for the corresponding information types. However, the collected information can also be used to estimate some of the other information types. For instance, there are several studies describing how to estimate the alighting stop based on historical data from detection at vehicle entrance or platform only (Wang et al. 2011; Munizaga and Palma 2012; Ma et al. 2013; Arnone et al. 2016). This means that the information types may either be collected in real-time, or be estimated (predicted) based on non-real-time data, possibly in combination with other types of real-time data, see Table 2.

Please note that the level of anonymity (A) is relevant for both Tables 1 and 2, whereas the ratio of travelers for which the information has to be known (B) in Table 1 has been reformulated as the ratio of travelers for which the information can be known (B) in Table 2. The reason for including the B-dimension in Table 1 is that some of the action decisions require information from all of the travelers, and some from only a part of the travelers. However, in Table 2, the ratio of travelers for which the information can be collected is to some extent dependent on how the different technical solutions are implemented. For instance, continuous detection may be implemented as a voluntary service-enabling personalized information provision to the traveler, or implemented as a mandatory service incorporated with the ticketing system. Therefore, the B-dimension is formulated as a requirement in Table 1, and as a possibility dependent on implementation, in Table 2.

Furthermore, an additional dimension, precision of the provided information $(\mathrm{C})$, has been added to Table 2. The highest achievable precision of the collected information is dependent on which technical solution is selected. For instance, detection at vehicle entrance or platform only, cannot provide exact information about the number of currently onboard travelers, since no information about traveler alighting is available. Therefore, it is relevant to include the $\mathrm{C}$-dimension in Table 2. Including the $\mathrm{C}$-dimension in Table 1 would not make sense, since decisions about all actions are of course better supported by the highest information precision possible.

The technical solutions in the first four rows of Table 2 have the potential to provide the same information types (depending on implementation). However, they differ in anonymity and precision of the information. For instance, information from detection at vehicle entrance or on platform can be used to estimate a traveler's entire future route, based on historical data from this or other travelers' routes. However, this requires at least anonymity level Aii; otherwise, historical routes cannot be identified. Information from detection at vehicle entrance and exit, on the other hand, can be used to calculate the number of onboard travelers. This does not require traveler identification, i.e. level $\mathrm{Ai}$ is sufficient. However, if the entire future route shall be estimated based on historical data, travelers must be followed, which means that at least anonymity level Aii is required. 
Continuous detection differs from the first four solutions in the sense that it possible to estimate the traveler's final destination, based on historical data. Furthermore, since these types of solutions have typically not been designed for ticketing purposes, they do not reveal any special needs.

Traditional tickets specifying complete journeys usually specify the entire route, including information on date and time. Furthermore, the identity of the traveler is often known, or at least he/she can be reached via some identification key. The same information types can be obtained by both tickets specifying complete journeys and zone-based tickets with detection at vehicle/PTS entrance; however, for zone-based tickets, the traveler's future route must be estimated based on historical data in combination with the geographical districts of the zones. Moreover, the level of anonymity also differs.

User-generated information from smartphone apps has the potential to provide all information types. The drawback with this solution is that it typically relies on the travelers providing relevant information voluntarily and manually. This means that the ratio of travelers for which the information can be known, is only partial. Tickets specifying complete journeys also provide partial information, since tickets that have been bought might not actually be used. However, this problem might be solved with mandatory ticket detection, for instance onboard, as mentioned above. The other technical solutions all have the potential to provide full information, if the technology applied is of sufficiently high quality.

\subsection{Analysis and discussion}

Tables 1 and 2 show the possible action decisions that can be taken by transport actors during unplanned disturbances, together with necessary information types, as well as a number of technical solutions for collecting these information types in real time. Hereby, we can assess which technical solutions can support which action decisions. As can be seen, the solutions support slightly different action decisions to different degrees. As an example of how the results can be used for analysis, we look at the replacement traffic planning/capacity allocation action decision. For this decision, traveler information about current vehicle and information about next intended vehicle to board are most valuable. These information types can be obtained by implementing any of the technical solutions listed in Table 2. However, for some of the solutions, both information types must be estimated, for some only the information about next intended vehicle to board needs to be estimated, and for some none of the information types have to be estimated. In the latter case, the solutions have the potential to provide exact information (depending on the implementation). The level of anonymity also differs between the solutions. Depending on the solution, information about current vehicle and information about next intended vehicle to board can be entirely anonymous, anonymous but individual activities can be traced via an identification key, or non-anonymous in the sense that the real identity is known or the individual person can be reached (contacted) in some way. For the other information types supporting the replacement traffic planning/capacity allocation action decision, different solutions provide different levels of support. Information about the next intended alighting point from vehicle and information 
about intended final PTS destination, may also be obtained by any of the technical solutions, whereas information about the intended final destination and information about special needs are only supported by some of the solutions (see Table 2). The information collected may be non-anonymous or anonymous but individual activities can be traced via an identification key.

Table 2 shows that all technical solutions enable provision of a relatively large share of the listed information types. Thereby, they also enable support for a relatively large share of action decisions. However, the level of anonymity, the ratio of travelers for which the information can be known, and the precision of the provided information differ between the solutions. This means that quality of the action decisions based on this information may vary. For instance, detection at vehicle entrance and exit, detection when onboard or continuous detection all have the potential to provide exact information about the number of travelers currently onboard, as opposed to detection at PTS entrance and exit and detection at vehicle entrance or on platform, which are only able to provide estimated information. This means that the action decisions dependent on this information-in particular, regular and replacement reallocations as well as priority/departure time replanning and emergency evacuation planning - cannot be based on exact information about the number of passengers. This may strongly violate the quality of these decisions. Thus, implementing, for instance, detection when onboard instead of detection at vehicle entrance or on platform might be preferable. Moreover, detection when onboard might be considered as an acceptable solution for the passengers, since it does not require any active actions from them.

The literature review shows that AFC is one of the most commonly implemented systems providing real-time information about the traveler. The AFC systems relevant for this study provide detection at PTS entrance and exit, detection at vehicle entrance or on platform, detection at vehicle entrance and exit, or detection when onboard. A comparison between Tables 1 and 2 reveals that the information that can be obtained from these systems, may provide sufficient support for all action decisions except the personalized traveler guidance and service decision (since information about the intended final destination, which is generally not supplied by AFC systems, is needed to provide personalized traveler guidance and service). However, some of the information have to be estimated, which means that the quality of the information might be poor. Another problem with AFC systems is that the collected data may not be complete due to fare evasion behaviors.

The technical solution providing the most extensive information, and thereby providing the best support for the action decisions, is user-generated information from smartphone apps. This solution involves an app, sending information related to the planned trip, including destination and route. The drawback with this solution is that it might violate privacy, if not properly implemented (due to anonymity level). Moreover, it typically relies on the travelers providing relevant information voluntarily, which may be of interest to very few travelers, thus resulting in partial information. Furthermore, since the penetration rates may differ among population segments, the information might be non-representative.

The technical solutions presented in this paper derive from previous studies and implemented systems. However, there may be other solutions suitable for collecting 
real-time information about travelers, with the purpose of supporting disturbance management. For instance, mobile phone positioning, social media analysis, or image processing of pictures taken by surveillance cameras, might also be considered as viable approaches. Moreover, AFC-systems with detection at an entrance of PTS only, have been excluded from this study, since more information than just the boarding point of an entire PTS is usually needed to obtain the lowest level of identified information. However, depending on practical settings (for instance, entrance at a single-line station) and availability of historical data, this might turn out as a valid approach after all.

In general, the value of real-time information naturally depends on the traveling variations in relation to a standard day as well as on the dynamics occurring due to disturbance. Has the same disturbance scenario occurred frequently before, the same actions might be repeatedly valid, which means that the need for real-time information decreases. However, we believe there is a general increased need for improved disturbance management, both because the travelers' demands continuously increase and because the actors see the potential benefits with an improved disturbance management. For instance, in Sweden there is a law saying that if a journey is more than $20 \mathrm{~min}$ delayed, the traveler is entitled to price reduction or compensation from the transport operator (Sveriges Riksdag 2015). This law highlights the need for efficient disturbance management and personalized traveler guidance (e.g. finding alternative routes).

It is outside the scope of this paper to analyze the degree of privacy invasiveness and potential violations of legal regulation, such as the EU General Data Protection Regulation (GDPR), induced by the different solutions. A short note on this is that it is most problematic to gather personal data for which no consent has been obtained from the travelers. In general, solutions relying on ticketing data consents can be achieved at the time of purchasing. However, we see it as potentially problematic to store historical information of entrance and exit points of PTSs, and use information for creating estimates of intended behaviors, since it may not be clear to the traveler that by, for instance, using a smartcard, the information will be utilized in this way. This raises questions concerning whether the traveler can ask for such information to be removed. Finally, information about special needs may also be sensitive to share with transport actors.

\section{Conclusions and future work}

The results presented in this paper enable a high level analysis of different solutions providing opportunities for supporting decisions about different actions relevant to take in cases of unplanned disturbances. The analysis suggests that:

- All technical solutions identified have the potential to provide a relatively large share of relevant information types, thus providing support for a relatively large share of action decisions. However, the quality of the decisions may vary, since the level of anonymity, the ratio of travelers for which the information can be known, and the precision of the provided information differ among the solutions. Moreover, it appears reasonable to use more than one solution for gathering data, since the solutions support slightly different actions to different degrees. 
- Automated Fare Collection (AFC) is one of the most commonly implemented systems providing real-time information about the traveler. AFC can provide support for a large number of action decisions relevant in disturbance scenarios. The AFC systems relevant for this study detect travelers at PTS entrance and exit, at vehicle entrance or on platform, at vehicle entrance and exit, or onboard. Of these, detection at vehicle entrance and exit or when onboard provide the best opportunities for obtaining better information.

- User-generated information provides the best opportunities for some types of action decisions, for instance, concerning personalized traveler guidance and service. However, these types of solutions potentially have the drawback of only providing partial information, meaning that the information is only available for a part of the travelers since some may be reluctant to provide this information. Moreover, the information might be incorrect or biased due to malicious information provision and potentially different penetration rates in different population segments.

- AFC systems might be a convenient choice for collecting information about travelers, since they are already widely deployed. However, the more activity required from the traveler by these systems (for instance, active check-ins and check-outs), the more incomplete the generated data might be, due to fare evasion. On the other hand, the less activity required from the traveler (for instance, detection when onboard), the more feelings of lost control and supervision the traveler might get. Travelers might feel less supervised with anonymous surveys based on detection when onboard, or APC systems. These technologies are continuously evolving to generate more precise detections. However, if they are completely anonymized, they may complicate or prohibit trip chaining.

In general, the literature review shows that only very few examples can be found of using real-time information about passengers in disturbance management, which indicates that this application area is underutilized. The results of this paper also indicate that there are clear potentials of using real-time information for disturbance management purposes. In particular, this study has identified a set of relevant action decisions which would benefit from real time information about travelers.

The paper provides managerial support for connecting relevant decision actions for a particular public transport system and relevant scenarios, to the most relevant information types that are needed for supporting these decision actions. Also, it supports the identification of the technical solutions needed for gathering relevant information in real time. The paper also provides managerial support to assess the potential of different ICT systems to support improved disturbance management via the potential information types such systems may generate. This may for instance influence the choices of ticketing systems.

The information from workshops and interviews presented in this paper has a Swedish perspective, which means that the identified action decisions probably mainly apply to deregulated public PTS based on competitive tendering. In Sweden, more than $90 \%$ of the total public transport supply is tendered out through competitive contract-awarding procurement methods (Vigren 2017). This means that open competition traffic operates alongside subsidized traffic. As a consequence of the 
deregulation, the number of actors has increased, and thereby also the number of decision levels and IT-systems, which has made the cooperation and coordination more challenging than before. Other countries in Central and Eastern Europe, such as Britain, Norway, Germany and Italy have also deregulated the public transport market (van de Velde 2014). Typically, the infrastructure is still maintained by a national authority. Other transport systems, for instance based on market initiatives where actors are free to initiate new transport services autonomously from specific actions or requests by (transport) authorities, may involve other/additional types of problems and decision actions than those presented in this paper.

Future work involves studies of privacy aspects and regulation compliance to, e.g. GDPR, as well as case studies of particular transport systems to investigate the potential to improve the disturbance management. Further studies on combining real-time information with historical data for supporting disturbance management could also be of relevance to be carried out. Moreover, this paper has highlighted the importance of information about special needs during public transport disturbances. This is also an area that needs more research. In particular, the questions of which information different special user groups require and how it best can be provided to them during traffic disturbances, should be subject to further investigation. The same information might very well be critical to a traveler with special needs but have much less, or no, impact on other travelers (e.g. information about a broken elevator). Therefore, more research focused on different special user groups is needed.

Acknowledgements Open access funding provided by Malmö University. This research has been funded by K2-The Swedish Knowledge Centre for Public Transport.

Open Access This article is distributed under the terms of the Creative Commons Attribution 4.0 International License (http://creativecommons.org/licenses/by/4.0/), which permits unrestricted use, distribution, and reproduction in any medium, provided you give appropriate credit to the original author(s) and the source, provide a link to the Creative Commons license, and indicate if changes were made.

\section{Appendix 1: Workshop questions}

1. What are the benefits of knowing where travelers currently are and where they are going, in unplanned disturbance situations? I.e. what can you, as an actor, do with this type of information and what are the benefits?

2. Are there any other types of information about the traveler (other than where travelers currently are and where they are going) that might be interesting in unplanned disturbance situations? In that case, what would this information enable? The information might, for instance, be generated from the traveler, from other actors or from IoT-based systems?

\section{Appendix 2: Interview and workshop answers}

See Tables 3, 4 and 5. 
Table 3 Identified problems related to lack of information about the traveler in unplanned disturbance management (problems are denoted as R1-R5)

\section{Problem Description}

R1 Today, there is no information about the number of travelers waiting on a platform for a train replacement bus, or onboard a certain train. Information about the types of travelers is thereby not available either (e.g. if there are school classes onboard). Such information would enable better planning. For instance, the bus capacity on regular lines, or the priorities made between different trains during a disturbance could be adapted to the number and types of travelers

R2 The train operator needs information about the number of onboard passengers, both in case of evacuation (in order to have enough personnel to handle the passengers) but also to be able to order enough train replacement bus capacity

R3 The bus operator has no information about to where train travelers are heading. If they knew, bus drivers could be told to wait for certain trains during disturbances

R4 Today, there is often no information about where onboard travelers are heading, in terms of their next stop and/or final destination, during a disturbance. Such information would allow for improved disturbance management (enable more informed decisions)

R5

Regular bus lines are almost never strengthened with extra buses during train disturbances, since the bus company lacks up-to-date information about train disturbances

Table 4 Identified potentials of having information about where travelers currently are and where they are going (question 1 in Appendix 1) (potentials are denoted as O1-O8)

\begin{tabular}{|c|c|}
\hline Potential & Description (information about where travelers currently are and where they are going) \\
\hline $\mathrm{O} 1$ & The ordering of the correct capacity of replacement traffic would be enabled \\
\hline $\mathrm{O} 2$ & $\begin{array}{l}\text { More personalized information to the traveler could be provided. For instance, the traveler } \\
\text { could be directed to the correct train replacement bus heading for the traveler's destination, } \\
\text { and the estimated travel time, for that traveler, could be provided }\end{array}$ \\
\hline $\mathrm{O} 3$ & Regular and replacement traffic would not have to visit all stops (some could be omitted) \\
\hline O4 & $\begin{array}{l}\text { Alternative routes adjusted to any personal needs of the traveler could be suggested. Amongst } \\
\text { others, this would lower the pressure on customer service }\end{array}$ \\
\hline O5 & Disturbance management could be made more efficient and optimized \\
\hline O6 & Correct priorities and consequence analyses could be made \\
\hline O7 & $\begin{array}{l}\text { The information could be used as statistical material for proactive work with, for instance, } \\
\text { connections, replacement traffic and traveler information }\end{array}$ \\
\hline O8 & $\begin{array}{l}\text { Personal information would enable validation of passenger presence, which could be used to } \\
\text { accept or reject delay compensations }\end{array}$ \\
\hline
\end{tabular}

Table 5 Identified potentials of having other types of information about the traveler (question 2 in Appendix 1) (potentials are denoted as O9-O10)

\begin{tabular}{ll}
\hline Potential & Description (other types of information about the traveler) \\
\hline O9 & $\begin{array}{l}\text { Information about special needs, for instance, disabilities, language difficulties or if the } \\
\text { traveler is a child, would enable more personalized traveler information and service }\end{array}$ \\
Information about special needs in terms of how critical it is for the traveler to reach its \\
final destination within a certain time limit (for instance, due to a leaving flight), could \\
be taken into account in the disturbance management
\end{tabular}




\section{References}

Arnone M, Delmastro T, Giacosa G, Paoletti M, Villata P (2016) The potential of e-ticketing for public transport planning: the Piedmont region case study. Transp Res Procedia 18:3-10

Barabino B, Di Francesco M, Mozzoni S (2014) An offline framework for handling automatic passenger counting raw data. IEEE Trans Intell Transp Syst 15(6):2443-2456

Barabino B, Salis S, Useli B (2015) What are the determinants in making people free riders in proof-ofpayment transit systems? Evidence from Italy. Transp Res Part A Policy Pract 80:184-196

Bucciol A, Landini F, Piovesan M (2013) Unethical behavior in the field: demographic characteristics and beliefs of the cheater. J Econ Behav Organ 93:248-257

Cacchiani V, Huisman D, Kidd M, Kroon L, Toth P, Veelenturf L, Wagenaar J (2014) An overview of recovery models and algorithms for real-time railway rescheduling. Transp Res Part B Methodol 63:15-37

Ceapa I, Smith C, Capra L (2012) Avoiding the crowds: understanding tube station congestion patterns from trip data. In: Proceedings of the ACM SIGKDD international workshop on urban computing, pp 134-141

Cohen-Blankshtain G, Rotem-Mindali O (2016) Key research themes on ICT and sustainable urban mobility. Int J Sustain Transp 10(1):9-17

Corman F, D’Ariano A, Marra AD, Pacciarelli D, Samà M (2017) Integrating train scheduling and delay management in real-time railway traffic control. Transp Res Part E Logist Transp Rev 105:213-239

Crawford D (2013) Making transit more passenger friendly. ITS Int 19(3):28-29

Currie G, Muir C (2017) Understanding passenger perceptions and behaviors during unplanned rail disruptions. Transp Res Procedia 25:4392-4402

Daduna JR, Voß S (1996) Efficient technologies for passenger information systems in public mass transit. In: Pirkul HP, Shaw MJ (eds) Proceedings of the first INFORMS conference on information systems and technology. INFORMS, Washington, pp 386-391

Delbosc A, Currie G (2016) Cluster analysis of fare evasion behaviours in Melbourne, Australia. Transp Policy 50:29-36

Deutsche Bahn (2017) Online ticket: easy, fast and convenient. https:/www.bahn.com/en/view/bookinginformation/booking/online-ticket.shtml. Accessed 13 Dec 2017

Ez-link (2017) EZ-Link Card System and Technology. http://www.ezlink.com.sg/about-ez-link/ez-linkcard-system-and-technology. Accessed 13 Dec 2017

Finžgar L, Trebar M (2011) Use of NFC and QR code identification in an electronic ticket system for public transport. In: Proceedings of the 19th IEEE international conference on software, telecommunications and computer networks (SoftCOM), pp 1-6

Fujiyama T, Cao B (2016) Lengths of time passengers spend at railway termini: an analysis using smart card data. In: Proceedings of the IEEE international conference on intelligent rail transportation (ICIRT), pp 139-144

Ghaemi N, Cats O, Goverde RM (2017) Railway disruption management challenges and possible solution directions. Public Transp 9(1-2):343-364

Handte M, Muñoz EM, Izquierdo S (2014) Crowd density estimation for public transport vehicles. In: Proceedings of the EDBT/ICDT workshops, pp 315-322

Hua W, Ong GP (2018) Effect of information contagion during train service disruption for an integrated rail-bus transit system. Public Transp 10(3):571-594

Ibarra-Rojas OJ, Delgado F, Giesen R, Muñoz JC (2015) Planning, operation, and control of bus transport systems: a literature review. Transp Res Part B Methodol 77:38-75

Jevinger Å, Persson JA (2016) Information-based disturbance management for public transport. Project report. http://www.k2centrum.se/sites/default/files/fields/field_uppladdad_rapport/informatio n-based_disturbance_management_for_public_transport_2016_15.pdf

Jevinger $\AA$, Persson JA (2019) Disturbance management and information availability in public transport, with focus on Scania County, Sweden. In: Bougdah H, Versaci A, Sotoca A, Trapani F, Migliore M, Clark N (eds) Urban and transit planning. Advances in science, technology \& innovation (IEREK Interdisciplinary Series for Sustainable Development). Springer, Cham, pp 305-311

Josyula SP, Törnquist Krasemann J (2017) Passenger-oriented railway traffic re-scheduling: a review of alternative strategies utilizing passenger flow data. In: Proceedings of the 7 th international conference on railway operations modelling and analysis 
Kiefer A, Kitzinger S, Doerner K (2016) Disruption management for the Viennese public transport provider. Public Transp 8(2):161-183

Kostakos V, Camacho T, Mantero C (2013) Towards proximity-based passenger sensing on public transport buses. Pers Ubiquit Comput 17(8):1807-1816

Kotz AJ, Kittelson DB, Northrop WF (2015) Novel vehicle mass-based automated passenger counter for transit applications. Transp Res Rec J Transp Res Board 2536:37-43

Lathia N, Capra L (2011) How smart is your smartcard? Measuring travel behaviours, perceptions, and incentives. In: Proceedings of the 13th international conference on ubiquitous computing, pp 291-300

Lathia N, Froehlich J, Capra L (2010) Mining public transport usage for personalised intelligent transport systems. In: Proceedings of the 10th IEEE international conference on in data mining (ICDM), pp $887-892$

Lau SL, Ismail SS (2015) Towards a real-time public transport data framework using crowd-sourced passenger contributed data. In: Proceedings of the 82nd IEEE vehicular technology conference (VTC Fall), pp 1-6

Lau JKS, Tham CK, Luo T (2011) Participatory cyber physical system in public transport application. In: Proceedings of the fourth IEEE international conference in utility and cloud computing (UCC), pp $355-360$

Lee RJ, Sener IN, Mullins JA III (2016) An evaluation of emerging data collection technologies for travel demand modeling: from research to practice. Transp Lett 8(4):181-193

Ma X, Wu YJ, Wang Y, Chen F, Liu J (2013) Mining smart card data for transit riders' travel patterns. Transp Res Part C Emerg Technol 36:1-12

Mayas C, Hörold S, Stelzer A, Englert F, Krömker H (2015) Evaluation of dispatcher requirements on automated customer feedback in public transport. In: Abascal J, Diniz Junqueira Barbosa S, Fetter M, Gross T, Palanque P, Winckler M (eds) Human-computer interaction-INTERACT 2015. Springer, Cham, pp 537-541

McLean H (2011) Deutsche Bahn to roll out Touch\&Travel across Germany. NFC World. https://www. nfcworld.com/2011/08/25/39363/deutsche-bahn-to-roll-out-touchtravel-across-germany/

McMullan A, Majumdar A (2012) Assessing the impact of travel path choice on London's rail network using an automatic fare collection system. Transp Res Rec J Transp Res Board 2274:154-163

Munizaga MA, Palma C (2012) Estimation of a disaggregate multimodal public transport Origin-Destination matrix from passive smartcard data from Santiago, Chile. Transp Res Part C Emerg Technol 24:9-18

Narzt W, Mayerhofer S, Weichselbaum O, Haselböck S, Höfler N (2015) Be-in/be-out with bluetooth low energy: Implicit ticketing for public transportation systems. In: Proceedings of the 18th IEEE international conference on intelligent transportation systems (ITSC), pp 1551-1556

Nikolić M, Teodorović D, Vukadinović K (2015) Disruption management in public transit: the bee colony optimization approach. Transp Plan Technol 38:1-19

Nitsche P, Widhalm P, Breuss S, Brändle N, Maurer P (2014) Supporting large-scale travel surveys with smartphones-a practical approach. Transp Res Part C Emerg Technol 43:212-221

Oberli C, Torres-Torriti M, Landau D (2010) Performance evaluation of UHF RFID technologies for realtime passenger recognition in intelligent public transportation systems. IEEE Trans Intell Transp Syst 11(3):748-753

Pelletier MP, Trépanier M, Morency C (2011) Smart card data use in public transit: a literature review. Transp Res Part C Emerg Technol 19(4):557-568

Shakibayifar M, Sheikholeslami A, Corman F (2018) A simulation-based optimization approach to reschedule train traffic in uncertain conditions during disruptions. Sci Iran 25(2):646-662

Skånetrafiken (2017) Skånetrafikens nya app. https://www.skanetrafiken.se/sa-reser-du-med-oss/skane trafikens-nya-app/. Accessed 13 Dec 2017

Stelzer A, Englert F, Hörold S, Mayas C (2014) Using customer feedback in public transportation systems. In: Proceedings of the IEEE international conference on advanced logistics and transport (ICALT), pp 29-34

Stelzer A, Englert F, Hörold S, Mayas C (2016) Improving service quality in public transportation systems using automated customer feedback. Transp Res Part E Logist Transp Rev 89:259-271

Stenneth L, Wolfson O, Yu PS, Xu B (2011) Transportation mode detection using mobile phones and GIS information. In: Proceedings of the 19th ACM SIGSPATIAL international conference on advances in geographic information systems, pp 54-63 
Sveriges Riksdag (2015) Lag (2015:953) om kollektivtrafikresenärers rättigheter. https://www.riksd agen.se/sv/Dokument-Lagar/Lagar/Svenskforfattningssamling/Lag-2015953-om-kollektivt ra_sfs-2015-953/?bet=2015:953

Törnquist J (2006) Computer-based decision support for railway traffic scheduling and dispatching: a review of models and algorithms. In: Proceedings of the 5th workshop on algorithmic methods and models for optimization of railways ATMOS

Uniman D, Attanucci J, Mishalani R, Wilson N (2010) Service reliability measurement using automated fare card data: application to the London underground. Transp Res Rec J Transp Res Board 2143:92-99

van de Velde D (2014) Market initiative regimes in public transport in Europe: recent developments. Res Transp Econ 48:33-40

van der Hurk E, Kroon L, Maróti G, Vervest P (2014) Deduction of passengers' route choices from smart card data. IEEE Trans Intell Transp Syst 16(1):430-440

van Oort N, Brands T, de Romph E (2015) Short term ridership prediction in public transport by processing smart card data. In: Proceedings of the 94th annual meeting of the Transportation Research Board, pp 105-111

Vigren A (2017) Competition in public transport. Dissertation, KTH Royal Institute of Technology

Wang W, Attanucci JP, Wilson NHM (2011) Bus passenger origin-destination estimation and related analyses. J Public Transp 14(4):131-150

Webster J, Watson RT (2002) Analyzing the past to prepare for the future: writing a literature review. MIS Q 26(2):xiii-xxiii

Zeller R (2013) Trapeze renews LIO operations control system in Leipzig. Trapeze Comput Mag 4:1-4

Zeng AZ, Durach CF, Fang Y (2012) Collaboration decisions on disruption recovery service in urban public tram systems. Transp Res Part E Logist Transp Rev 48(3):578-590

Zhao J, Rahbee A, Wilson NH (2007) Estimating a rail passenger trip origin-destination matrix using automatic data collection systems. Comput Aided Civ Infrastruct Eng 22(5):376-387

Zhao J, Zhang F, Tu L, Xu C, Shen D, Tian C, Li X, Li Z (2017) Estimation of passenger route choice pattern using smart card data for complex metro systems. IEEE Trans Intell Transp Syst 18(4):790-801

Zhong C, Batty M, Manley E, Wang J, Wang Z, Chen F, Schmitt G (2016) Variability in regularity: mining temporal mobility patterns in London, Singapore and Beijing using smart-card data. PLoS One 11(2): 0149222

Zöscher L, Grosinger J, Spreitzer R, Muehlmann U, Gross H, Bösch W (2015) Concept for a security aware automatic fare collection system using HF/UHF dual band RFID transponders. In: Proceedings of the 45th European solid state device research conference (ESSDERC), pp 194-197

Publisher's Note Springer Nature remains neutral with regard to jurisdictional claims in published maps and institutional affiliations. 